\title{
Calorie 15 Degrees Celsius
}

National Cancer Institute

\section{Source}

National Cancer Institute. Calorie 15 Degrees Celsius. NCI Thesaurus. Code C68843.

A non-SI unit of energy defined as the amount of heat required to raise the temperature of one gram of pure water by one degree (from 14.5 to $15.5 \mathrm{C}$ or from 287.65 to 288.65 K) under standard conditions with the specific heat of the water at 15 degrees Celsius and the constant pressure of $101.325 \mathrm{kPa}$ or one atm being defined as unity. A value recorded by ISO for the calorie at 15 degrees Celsius is $4.1855 \mathrm{~J}$. According to the current national standard in the United States (IEEE/AST M SI 10T M 2002. American National Standard for Use of the International System of Units (SI): The Modern Metric System, New York: IEEE, 2002) the calorie in any form is not to be used. Joules should be used instead. 